\title{
A comparative study to distinguish the vineyard of origin by NIRS using entire grapes, skins and seeds
}

\author{
Raúl Ferrer-Gallego, José Miguel Hernández-Hierro, ${ }^{\dagger}$ Julián C Rivas-Gonzalo \\ and $M$ Teresa Escribano-Bailón*
}

\begin{abstract}
BACKGROUND: Interest in high-quality products with a clear geographical origin is increasing. For the wine industry and market sector, identity preservation is of fundamental importance owing to the large number of geographical classifications. Nowadays, there is a growing demand for analytical methods for tracing grapes and wines. In the oenological sector, infrared spectroscopy is becoming an attractive tool allowing simultaneous measurement of several analytical parameters and enabling real-time decision making.

RESULTS: Discriminant partial least squares, a supervised pattern recognition technique, was employed to discriminate between vineyards of origin using the near-infrared spectra of intact grapes, skins or seeds. In order to compare the three sample presentations, a receiver operating characteristic curve was used. The best results were obtained using intact grape seeds, with prediction rates of samples correctly classified of about $95 \%$, although the good results obtained with entire grapes (about $93 \%$ of samples correctly classified) and the simplicity of use of the fibre optic probe could advise using entire grape presentation for comprehensive studies.

CONCLUSION: The procedure reported here seems to have excellent potential for a fast and reasonably inexpensive analysis of the origin of samples. It is noted that such classification can be made at any time of ripening. This paper provides information of interest to develop new and extensive models in the future.

(c) 2012 Society of Chemical Industry
\end{abstract}

Keywords: near-infrared spectroscopy; phenolic compounds; grapes; vineyards

\section{INTRODUCTION}

Nowadays, interest in high-quality products with a clear geographical origin is increasing. For the wine industry and market sector, identity preservation is of fundamental importance owing to the large number of geographical classifications. In this framework, there is a growing demand for analytical methods for tracing grapes and wines.

Numerous analytical tools coupled with chemometics have been tested in order to achieve this aim. ${ }^{1-4}$ Among them, phenolic compounds coupled with colour and other oenological parameters have been used to recognise wine grape cultivars in German red wines, ${ }^{5}$ Greek red wines, ${ }^{6}$ South African red and white wines ${ }^{7}$ and Spanish red and rosé wines ${ }^{8-10}$ and also to differentiate between different production areas. ${ }^{6,11,12}$

In the oenological sector, infrared spectroscopy is becoming an attractive tool applicable to both the raw material and the end product, allowing simultaneous measurement of several analytical parameters and enabling real-time decision making. ${ }^{13}$ It has been employed for quantitative purposes in order to determine a number of oenological parameters such as phenolic compounds, organic acids, polysaccharides, alcohol concentration, acidity, $\mathrm{pH}$, acetic acid, reducing sugars, mineral elements and aromas, among others. ${ }^{13-21}$ Regarding qualitative analysis, the aforementioned technique has also been used to classify organic and nonorganic wines, ${ }^{22}$ to discriminate between wines of different varietal origin, ${ }^{23-25}$ to detect fermentation problems, ${ }^{26,27}$ to discriminate between wines contaminated or not contaminated with Brettanomyces bruxellensis ${ }^{28}$ and to distinguish between wines of different geographical origin. ${ }^{29,30}$ Regarding grapes, the technique has been employed to classify grapes according to their geographic location, achieving promising results. ${ }^{31-33}$

The main objective of the present study was to compare the potential of different sample presentation forms from grapes to specify their vineyard of origin using near-infrared (NIR) technology. To our knowledge, this is the first time that a

* Correspondence to: M Teresa Escribano-Bailón, Grupo de Investigación en Polifenoles, Unidad de Nutrición y Bromatología, Facultad de Farmacia, Universidad de Salamanca, Campus Miguel de Unamuno, E-37007 Salamanca, Spain.E-mail:escriban@usal.es

+ Food Colour and Quality Laboratory, Department of Nutrition and Food Science, Facultad de Farmacia, Universidad de Sevilla, E-41012 Sevilla, Spain.

Grupo de Investigación en Polifenoles, Unidad de Nutrición y Bromatología, Facultad de Farmacia, Universidad de Salamanca, Campus Miguel de Unamuno, E-37007 Salamanca, Spain 
comparative study between entire grapes, skins and seeds has been evaluated with this purpose. Two ways to record the NIR spectra, namely transport quartz cup (skins and seeds) and fibre optic probe (intact grapes), were used.

Furthermore, in order to obtain information about the chemical basis of the discrimination, attention was paid to the relationship between the spectral variability and the phenolic compounds present in grape skins and seeds.

\section{MATERIALS AND METHODS}

\section{Samples}

Vitis vinifera L. cv. Graciano red grape samples were collected from two different vineyards located in La Rioja (Spain). POD La Rioja is divided into regions according to their agroclimatic characteristics. Vineyard 1 is located in Logroño (Rioja Media) and vineyard 2 is located $40 \mathrm{~km}$ away in Haro (Rioja Alta). The first region is under the influence of a Mediterranean climate, while Rioja Alta generally is cooler and is under the influence of an Atlantic climate. Differences between the agroclimatic conditions of the regions have been described previously. ${ }^{34}$

The samples were collected at different developmental stages from veraison (September) to overripeness (November) in two different vintages (2008 and 2009). In the case of the 2008 vintage, seven dates were taken into account for vineyard 1 and eight for vineyard 2. For the 2009 vintage the number of dates taken into account was six for vineyard 1 and seven for vineyard 2 . Three groups of 150 berries per vineyard were collected at each date. A total of 84 samples were collected in this study, corresponding to 39 samples from vineyard 1 and 45 samples from vineyard 2 . The berries were collected from both sides of vines located in different rows within the vineyard. Edge rows and the first two vines in a row were avoided. Berries were collected from the top, middle and bottom of the cluster and were immediately frozen and stored at $-20^{\circ} \mathrm{C}$ until analyses were performed. Firstly, the samples were thawed and tempered at room temperature and the NIR spectra of the intact grapes were recorded at room temperature, which was controlled by an air-conditioning device. Grape skins and seeds were then separated manually from the whole grapes, and the remaining pulp was removed with the aid of filter paper in the case of grape seeds. Two subsamples were taken from each sample, one for analysis by high-performance liquid chromatography with diode array detection/mass spectrometry (HPLC-DAD/MS) and the other for NIR analysis, which was also carried out at room temperature. ${ }^{20,21}$

\section{Near-infrared spectroscopy analysis}

A (Foss, Silver Spring, USA) Foss NIRSystem 5000 was used to perform the near-infrared spectroscopy (NIRS) analysis. The spectra were recorded at intervals of $2 \mathrm{~nm}$, performing 32 scans for both reference and samples. The fibre optic probe type 210/210 of $1.5 \mathrm{~m}$ length (Ref. R6539-A) employs a remote reflectance system and a ceramic plate as reference. The window is of quartz with a $5 \mathrm{~cm} \times 5 \mathrm{~cm}$ surface area, measuring reflectance in the NIR zone over a wavelength range of $1100-2000 \mathrm{~nm}$. The fibre optic probe increases the signal/noise ratio above $2000 \mathrm{~nm}$ as a consequence of -OH groups present in the fibre optic material. The recommended spectral zone for this attachment is $1100-2000 \mathrm{~nm}$. The NIR spectra were recorded by direct application of the fibre optic probe onto the intact grapes. Approximately 10-15 grapes $(\sim 20-30 \mathrm{~g})$ selected randomly were used to record their average spectrum. The whole data set was constituted by 84 intact grape samples and $451 \log (1 / R)$ data points per sample.

A transport quartz cup with a window surface area of $4.7 \mathrm{~cm} \times$ $5.7 \mathrm{~cm}$ and an optical pathway of $1.7 \mathrm{~cm}$ was used in half-full mode (i.e. grape skins or seeds covering half of the window surface) to record the reflectance spectra of grape skins and seeds. In this case the measurements were made in the NIR zone over a wavelength range of $1100-2498 \mathrm{~nm}$. The whole data set was constituted by 84 grape skin or seed samples and $700 \log (1 / R)$ data points per sample. The software used was Win ISI ${ }^{\mathrm{TM}}$ Version 1.50 (Infrasoft International, LLC, Port Matilda, PA, USA).

\section{Phenolic compound analysis by HPLC-DAD/MS}

In order to obtain information about the chemical basis of the discrimination, analysis of the phenolic composition of grape skins and seeds was performed as described by Ferrer-Gallego et al. ${ }^{20,21,35}$

Briefly, grape seeds and skins were separated manually and submitted to two different extraction procedures, with $750 \mathrm{~mL}$ $\mathrm{L}^{-1}$ methanol and acidic methanol respectively. In the case of flavanols and phenolic acids from grape skins, an additional cleanup procedure using a cationic exchange cartridge was performed prior to the HPLC-DAD/MS analysis. ${ }^{20,21,35}$ Up to 77 phenolic compounds were determined: 47 flavanols, 13 anthocyanins, nine flavonols and eight phenolic acids. All analyses were performed in triplicate.

\section{Chemometric techniques}

The software used was Win ISI ${ }^{\mathrm{TM}}$ Version 1.50 (Infrasoft International, LLC), which allows not only spectral acquisition but also data treatment and the development of qualitative models. From the three samples of each date, one $(33 \%)$ was allocated to the validation set and the other two (66\%) to the calibration set. A supervised pattern recognition technique, with a priori knowledge about the category membership of samples, was employed in the qualitative analysis. Discriminant partial least squares (DPLS) was used, which permits the modelling of classes. Modelling of the groups was carried out using the NIR raw spectral data and one dummy variable, whose values were 1 and 2, thus the explicit algebraic models denominated DPLS were constructed. The calibration was conducted by performing a regression on the spectral information on all group values, in this case defined as 1 or 2 (vineyard 1 or 2). The regression method applied to this procedure is MPLS, which is a modification of normal PLS 1. ${ }^{36,37}$ The vineyard discriminant model using grape seeds has already been developed as described elsewhere. ${ }^{21}$ In order to compare the three sample presentations, a receiver operating characteristic (ROC) curve - a graphical approach for displaying the trade-off between true positive rate and false positive rate of a classifier - was used.

Moreover, in order to obtain information about the relationship between the spectral variability and the phenolic composition, principal component analysis (PCA) and Pearson correlation analysis were carried out. PCA could also be used in further analysis in order to detect samples that do not belong to the spectral group using the Mahalanobis distance prior to the discriminant analysis. PCA was performed with the NIR spectral data. Pearson correlations between the scores of the first principal component and the analysed phenolic compounds of each sample presentation were performed. Only the phenolic composition of grape skins was considered for intact grapes, since NIR radiation does not penetrate enough to use also the phenolic composition 
Table 1. Statistical description of DPLS models

\begin{tabular}{lccccc} 
Presentation & PLS factors & $\begin{array}{c}\text { Cross-validation } \\
\text { groups }\end{array}$ & RSQ & SEC & SECV \\
\hline Grape seeds & 11 & 6 & 0.718 & 0.27 & 0.33 \\
Intact grapes & 9 & 6 & 0.647 & 0.30 & 0.33 \\
Grape skins & 2 & 6 & 0.217 & 0.45 & 0.44 \\
\hline
\end{tabular}

$\mathrm{RSQ}$, coefficient of determination; SEC, standard error of calibration; SECV, standard error of cross-validation.

of grape seeds. The radiation applied by most instruments has very little energy and only penetrates a millimetre or so into the substance, depending on the substance surface composition and structure. $^{38}$

The SPSS 13.0 for Windows software package (SPSS, Inc., Chicago, IL, USA) was used for Pearson correlation and ROC curve analyses.

\section{RESULTS AND DISCUSSION}

Figure 1 shows the average spectrum of each vineyard in the NIR zone (A) between 1100 and $2000 \mathrm{~nm}$ for intact grapes and (B) between 1100 and $2500 \mathrm{~nm}$ for grape skins and seeds. Differences between each vineyard average spectrum were observed, especially in the case of grape seed samples. This suggests that this sample presentation may provide the best classification results.

The vineyard discriminant model using grape seeds has already been developed as described elsewhere. ${ }^{21}$ The number of PLS factors was set using the cross-validation procedure; in this case, six cancellation groups were used (this number is greater in this method compared with normal PLS). The discriminant models using grape skins and intact grapes were developed following the same procedure and the results are presented in Table 1.

As previously established, ${ }^{21}$ the spectral regions $1100-1358$ and $1800-2100 \mathrm{~nm}$ showed important contributions to the grape seed model loadings and are mainly related to second overtones of $\mathrm{C}-\mathrm{H}$ and second overtones of the bonds present in the $\mathrm{COOH}$ groups respectively. ${ }^{39,40}$ Regarding the intact grape model, the most important spectral regions were $1100-1552,1274-1600$ and

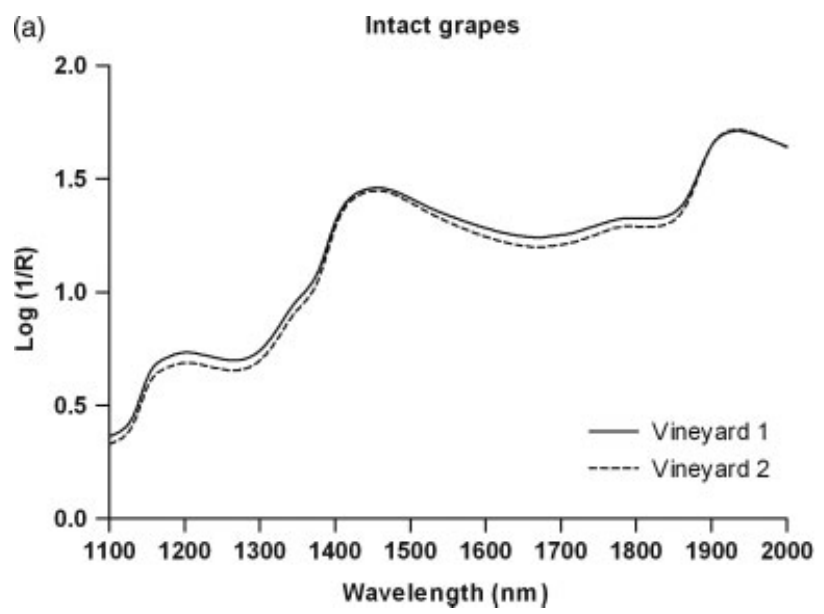

1856-2000 nm. As for grape skins, the spectral regions 1140-1250, $1370-1500$ and $1800-1955 \mathrm{~nm}$ showed important contributions to the model loadings. The first and third spectral zones of these models mainly match the zones previously described for the grape seed model. The second zones (i.e. 1274-1600 nm for intact grapes and $1370-1500 \mathrm{~nm}$ for grape skins) are essentially related to combination bands of aromatic $\mathrm{C}-\mathrm{H}$ groups and first overtones of the aforementioned bonds. ${ }^{39,40}$

In order to evaluate the NIRS technology models, an internal validation was carried out using samples that belonged to the calibration group. An external validation was also performed to check the predictive ability of the method using the 28 samples that did not belong to the calibration group. Table 2 presents the obtained results expressed as number and prediction rate of samples correctly classified. The percentages of samples correctly classified using the DPLS models were $66 \%$ in internal validation and $68 \%$ in external validation in the case of grape skins and $93 \%$ and $83 \%$ in internal and external validation respectively in the case of intact grapes. The best results were obtained using intact grape seeds, with prediction rates of samples correctly classified of $95 \%$ in internal validation and $97 \%$ in external validation. In consequence, as can be seen in the ROC curves (Fig. 2), the greatest area under the curve in both cases, internal and external validation, was for grape seeds. Also noticeable is the area for entire grapes, which is in internal validation not so much different from that of seeds. Even if the results indicate that grape seeds are the most adequate matrix to perform NIRS analysis in order to specify the vineyard origin of grapes, the good results obtained with entire grapes and the simplicity of the use of the fibre optic probe (the probe is placed directly on the berries and no further manipulation of the sample is needed) could advise using entire grape presentation for comprehensive studies.

Table 3 lists the phenolic compounds and families of phenolic compounds used in the Pearson correlation analysis. For this analysis, these compounds were grouped taking into account their basic structures. Considering the good results obtained with grape seeds, major individual flavanols from seeds were also considered.

In the space defined by the PCA of the data from skins, principal component 1 (PC1) explains $75.3 \%$ of spectral variability and its scores showed significant correlations (0.01, two-tailed) with anthocyanins and total phenolic compounds. Significant

(b)

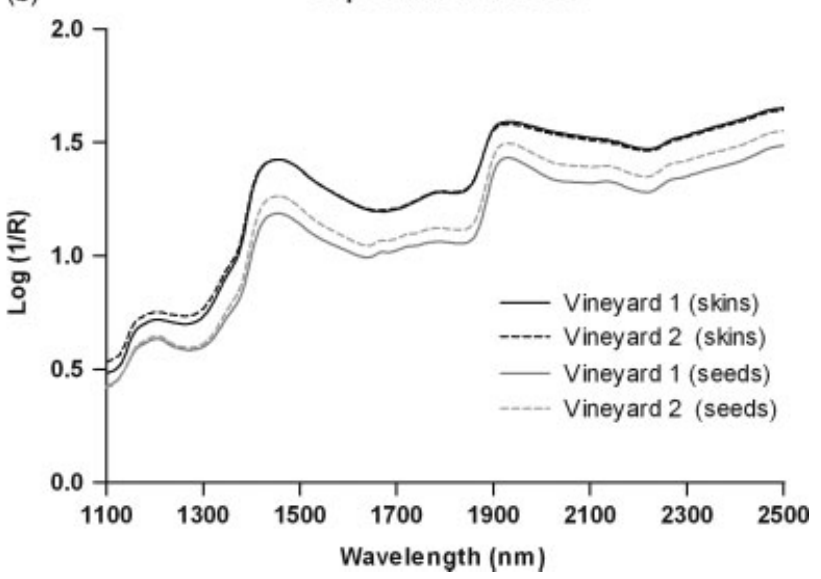

Figure 1. Average spectrum of each vineyard in NIR zone (A) between 1100 and $2000 \mathrm{~nm}$ for intact grapes and (B) between 1100 and $2500 \mathrm{~nm}$ for grape skins and seeds. 
Table 2. Classification of samples according to their vineyard of origin. Internal and external validation

Samples correctly classified

\begin{tabular}{|c|c|c|c|c|c|c|}
\hline \multirow[b]{2}{*}{ Item } & \multicolumn{2}{|c|}{ Intact grapes } & \multicolumn{2}{|c|}{ Grape skins } & \multicolumn{2}{|c|}{ Grape seeds } \\
\hline & Vineyard 1 & Vineyard 2 & Vineyard 1 & Vineyard 2 & Vineyard 1 & Vineyard 2 \\
\hline Internal validation & $24 / 26$ & $28 / 30$ & $16 / 26$ & $21 / 30$ & $24 / 26$ & $29 / 30$ \\
\hline Percentage (\%) ${ }^{\mathrm{a}}$ & 92 & 93 & 62 & 70 & 92 & 97 \\
\hline Total internal (\%) & \multicolumn{2}{|c|}{93} & \multicolumn{2}{|c|}{66} & \multicolumn{2}{|c|}{95} \\
\hline External validation & $11 / 13$ & $12 / 15$ & $8 / 13$ & $11 / 15$ & $13 / 13$ & $14 / 15$ \\
\hline Percentage (\%) ${ }^{\mathrm{a}}$ & 85 & 80 & 62 & 73 & 100 & 93 \\
\hline Total external (\%) & \multicolumn{2}{|c|}{83} & \multicolumn{2}{|c|}{68} & \multicolumn{2}{|c|}{97} \\
\hline
\end{tabular}

a Prediction rate of samples correctly classified.
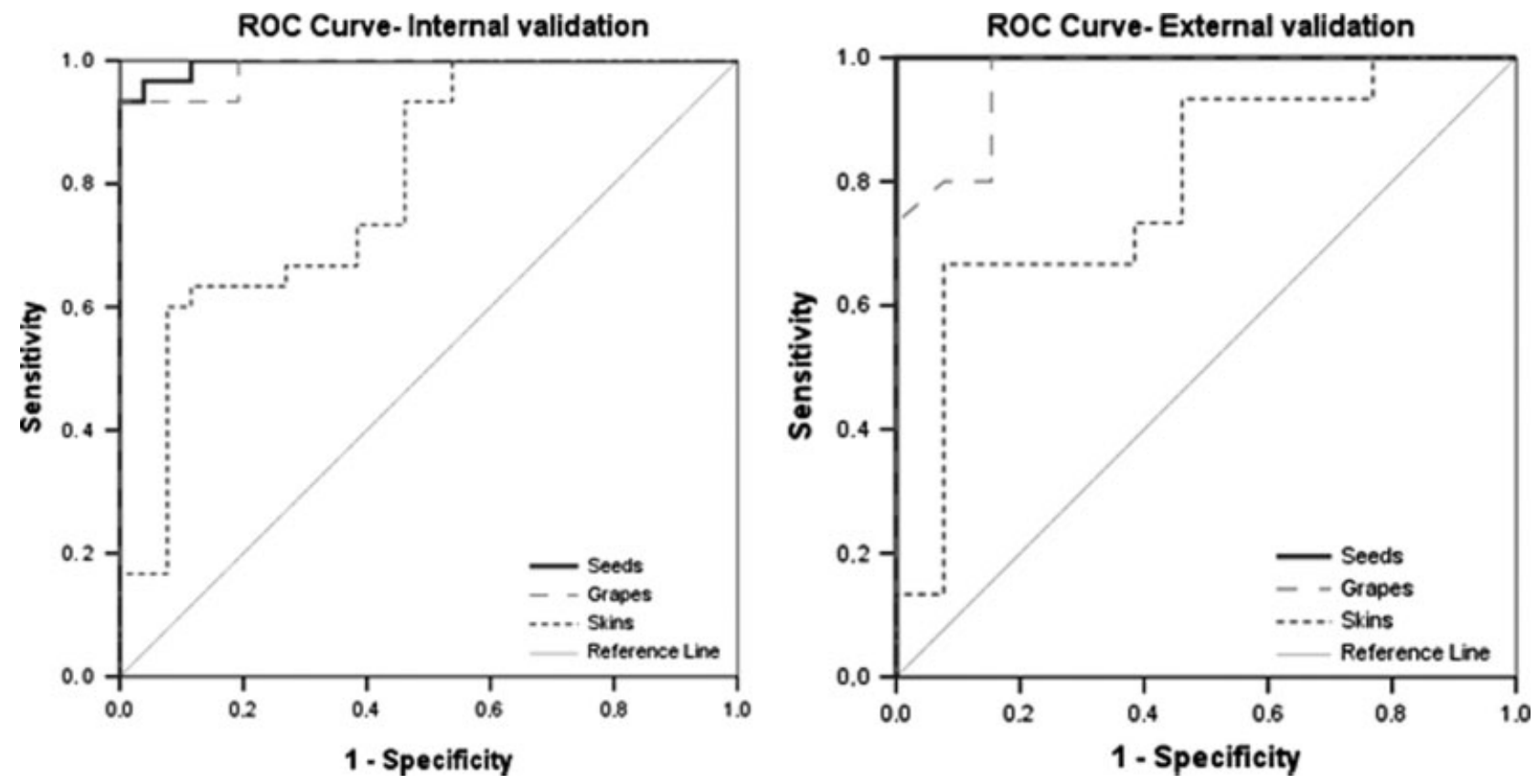

Figure 2. Receiver operating characteristic (ROC) curves. Internal and external validation.

correlations with flavonols and phenolic acids were also found (0.05, two-tailed) (Table 3).

In the case of entire grapes, PC1 explains $86.5 \%$ of spectral variability and its scores showed significant correlations (0.01, twotailed) with anthocyanins, flavanols and total phenolic compounds. Significant correlations ( 0.05 , two-tailed) with flavonols were also observed (Table 3).

PC1 for seeds explains $92.4 \%$ of spectral variability and its scores showed significant correlations (0.01, two-tailed) with all studied phenolic compounds except dimer B2 and galloylated trimers (Table 3).

\section{CONCLUSION}

The comparative study between the three sample presentation ways to be used for distinguishing the vineyard of origin using NIR technology shows that seeds are the best matrix to carry out the classification, although the good results obtained with entire grapes and the simplicity of the use of the fibre optic probe could advise using entire grape presentation for comprehensive studies. Measuring intact grapes directly could be an excellent tool for a fast and non-destructive analysis. It is noticeable that this classification can be made at any time of ripening.

This study may help to develop robust models in the future. Nevertheless, a comprehensive study should be done in order to evaluate factors such as different production areas and grape varieties.

\section{ACKNOWLEDGEMENTS}

Thanks are due to the Spanish MICINN (projects AGL2008-05569C02 and AGL2011-30254-C02 and FPI predoctoral scholarship to R Ferrer-Gallego), the Junta de Castilla y León (group GR133), the Consolider project and the OIV for financial support. JM Hernández-Hierro thanks the Spanish MICINN for the Juan de la Cierva contract (JCl-2011-09201). The authors also thank Bodegas RODA SA (Haro, La Rioja, Spain) for supplying the grape samples, as well as Dr I González-Martín who kindly allowed us to use the NIRS instrument. 
Table 3. Pearson correlations between phenolic composition and scores of first principal component (PCA performed with NIRS data)

\begin{tabular}{|c|c|c|c|c|}
\hline \multirow[b]{2}{*}{ Grape skins } & \multicolumn{2}{|c|}{ Pearson correlation } & \multirow[b]{2}{*}{ Grape seeds } & \multirow{2}{*}{$\frac{\text { Pearson correlation }}{\text { PC1 seeds }}$} \\
\hline & PC1 skins & PC1 grapes & & \\
\hline Anthocyanins & $-0.370 * *$ & $0.482^{* *}$ & Total monomers & $0.844^{* *}$ \\
\hline Phenolic acids & $-0.312^{*}$ & 0.126 & Total dimers & $0.579^{* *}$ \\
\hline Flavanols & -0.241 & $0.583^{* *}$ & Total trimers & $0.583^{* *}$ \\
\hline Flavonols & $-0.316^{*}$ & $0.291 *$ & Total tetramers & $0.579^{* *}$ \\
\hline \multirow[t]{13}{*}{ Total phenolic compounds } & $-0.349^{* *}$ & $0.557^{* *}$ & Total galloylated dimers & $0.816^{* *}$ \\
\hline & & & Total galloylated trimers & 0.106 \\
\hline & & & Total galloylated compounds & $0.663^{* *}$ \\
\hline & & & Total phenolic compounds & $0.810^{* *}$ \\
\hline & & & $(+)$-Catechin & $0.807^{* *}$ \\
\hline & & & (-)-Epicatechin & $0.663^{* *}$ \\
\hline & & & B1 & $0.639^{* *}$ \\
\hline & & & B2 & -0.127 \\
\hline & & & B3 & $0.373^{* *}$ \\
\hline & & & B4 & $0.755^{* *}$ \\
\hline & & & EEC & $0.663^{* *}$ \\
\hline & & & ECG & $0.741^{* *}$ \\
\hline & & & B23G & $0.686^{* *}$ \\
\hline
\end{tabular}

B1, epicatechin- $(4 \beta \rightarrow 8)$-catechin; B2, epicatechin-( $4 \beta \rightarrow$ 8)-epicatechin; B3, catechin-( $4 \alpha \rightarrow 8)$-catechin; B4, catechin-(4 $\beta \rightarrow 8)$-epicatechin; EEC, epicatechin- $(4 \beta \rightarrow 8)$-epicatechin- $(4 \beta \rightarrow 8)$-catechin; ECG, epicatechin 3 - O-gallate; B23G, B23 - O-gallate.

* Pearson correlation significant at 0.05 level;

** Pearson correlation significant at 0.01 level.

\section{REFERENCES}

1 Berrueta LA, Alonso-Salces RM and Heberger K, Supervised pattern recognition in food analysis. J Chromatogr A 1158:196-214 (2007).

2 Kelly S, Heaton K and Hoogewerff J, Tracing the geographical origin of food: the application of multi-element and multi-isotope analysis. Trends Food Sci Technol 16:555-567 (2005).

3 Luykx DMAM and van Ruth SM, An overview of analytical methods for determining the geographical origin of food products. Food Chem 107:897-911 (2008).

4 Reid LM, O'Donnell CP and Downey G, Recent technological advances for the determination of food authenticity. Trends Food Sci Technol 17:344-353 (2006).

5 Berente B, De la Calle García D, Reichenbächer M and Danzer K, Method development for the determination of anthocyanins in red wines by high-performance liquid chromatography and classification of German red wines by means of multivariate statistical methods. J Chromatogr A 871:95-103 (2000).

6 Makris DP, Kallithraka S and Mamalos A, Differentiation of young red wines based on cultivar and geographical origin with application of chemometrics of principal polyphenolic constituents. Talanta 70:1143-1152 (2006).

7 De Villiers A, Majek P, Lynen F, Crouch A, Lauer H and Sandra P, Classification of South African red and white wines according to grape variety based on the non-coloured phenolic content. Eur Food Res Technol 221:520-528 (2005).

8 Almela L, Javaloy S, Fernández-López JA and López-Roca JM, Varietal classification of young red wines in terms of chemical and colour parameters. J Sci Food Agric 70:173-180 (1996).

9 García-Marino M, Hernández-Hierro JM, Santos-Buelga C, RivasGonzalo JC and Escribano-Bailón MT, Multivariate analysis of the polyphenol composition of Tempranillo and Graciano red wines. Talanta 85:2060-2066 (2011).

10 Pérez-Magariño S, Ortega-Heras M, González-San José ML and Boger Z, Comparative study of artificial neural network and multivariate methods to classify Spanish DO rose wines. Talanta 62:983-990 (2004).

11 Rodríguez-Delgado M-Á, González-Hernández G, Conde-González J$E$ and Pérez-Trujillo J-P, Principal component analysis of the polyphenol content in young red wines. Food Chem 78:523-532 (2002).
12 Kallithraka S, Mamalos A and Makris DP, Differentiation of young red wines based on chemometrics of minor polyphenolic constituents. J Agric Food Chem 55:3233-3239 (2007).

13 Fernandez-Novales J, Lopez MI, SanchezMT, Morales J and Gonzalez-Caballero V, Shortwave-near infrared spectroscopy for determination of reducing sugar content during grape ripening, winemaking, and aging of white and red wines. Food Res Int 42:285-291 (2009).

14 Boulet JC, Williams $P$ and Doco T, A Fourier transform infrared spectroscopy study of wine polysaccharides. Carbohydr Polym 69:79-85 (2007).

15 Jensen JS, Egebo M and Meyer AS, Identification of spectral regions for the quantification of red wine tannins with Fourier transform mid-infrared spectroscopy. JAgric Food Chem 56:3493-3499 (2008).

16 Moreira JL and Santos L, Analysis of organic acids in wines by Fouriertransform infrared spectroscopy. Anal Bioanal Chem 382:421-425 (2005).

17 Patz CD, Blieke A, Ristow R and Dietrich H, Application of FT-MIR spectrometry in wine analysis. Anal Chim Acta 513:81 - 89 (2004).

18 Smyth HE, Cozzolino D, Cynkar WU, Dambergs RG, Sefton M and Gishen M, Near infrared spectroscopy as a rapid tool to measure volatile aroma compounds in Riesling wine: possibilities and limits. Anal Bioanal Chem 390:1911 - 1916 (2008).

19 Urbano-Cuadrado M, Luque de Castro MD, Perez-Juan PM, GarciaOlmo J and Gomez-Nieto MA, Near infrared reflectance spectroscopy and multivariate analysis in enology - determination or screening of fifteen parameters in different types of wines. Anal Chim Acta 527:81 - 88 (2004).

20 Ferrer-Gallego R, Hernández-Hierro JM, Rivas-Gonzalo JC and Escribano-Bailón MT, Determination of phenolic compounds of grape skins during ripening by NIR spectroscopy. LWT-Food Sci Technol 44:847-853 (2011).

21 Ferrer-Gallego R, Hernández-Hierro JM, Rivas-Gonzalo JC and Escribano-Bailón MT, Feasibility study on the use of near infrared spectroscopy to determine flavanols in grape seeds. Talanta 82:1778-1783 (2010).

22 Cozzolino D, Holdstock M, Dambergs RG, Cynkar WU and Smith PA, Mid infrared spectroscopy and multivariate analysis: a tool to discriminate between organic and non-organic wines grown in Australia. Food Chem 116:761 - 765 (2009). 
23 Tarantilis PA, Troianou VE, Pappas CS, Kotseridis YS and Polissiou MG, Differentiation of Greek red wines on the basis of grape variety using attenuated total reflectance Fourier transform infrared spectroscopy. Food Chem 111:192-196 (2008).

24 Cozzolino D, Smyth HE and Gishen M, Feasibility study on the use of visible and near-infrared spectroscopy together with chemometrics to discriminate between commercial white wines of different varietal origins. J Agric Food Chem 51:7703-7708 (2003).

25 Louw L, Roux K, Tredoux A, Tomic O, Naes T, Nieuwoudt HH, et al, Characterization of selected South African young cultivar wines using FTMIR spectroscopy, gas chromatography, and multivariate data analysis. J Agric Food Chem 57:2623-2632 (2009).

26 Urtubia A, Perez-Correa JR, Pizarro F and Agosin E, Exploring the applicability of MIR spectroscopy to detect early indications of wine fermentation problems. Food Control 19:382-388 (2008).

27 Oliveri P, Di Egidio V, Woodcock T and Downey G, Application of classmodelling techniques to near infrared data for food authentication purposes. Food Chem 125:1450-1456 (2011).

28 Oelofse A, Malherbe S, Pretorius IS and Du Toit M, Preliminary evaluation of infrared spectroscopy for the differentiation of Brettanomyces bruxellensis strains isolated from red wines. Int J Food Microbiol 143:136-142 (2010).

29 Liu L, Cozzolino D, Cynkar WU, Gishen M and Colby CB, Geographic classification of Spanish and Australian Tempranillo red wines by visible and near-infrared spectroscopy combined with multivariate analysis. J Agric Food Chem 54:6754-6759 (2006).

30 Bevin CJ, Dambergs RG, Fergusson AJ and Cozzolino D, Varietal discrimination of Australian wines by means of mid-infrared spectroscopy and multivariate analysis. Anal Chim Acta 621:19-23 (2008).

31 Herrera J, Guesalaga A and Agosin E, Shortwave-near infrared spectroscopy for non-destructive determination of maturity of wine grapes. Meas Sci Technol 14:689-697 (2003).
32 Le Moigne M, Maury C, Bertrand D and Jourjon F, Sensory and instrumental characterisation of Cabernet Franc grapes according to ripening stages and growing location. Food Qual Prefer 19:220-231 (2008).

33 Arana I, Jaren C and Arazuri S, Maturity, variety and origin determination in white grapes (Vitis vinifera L.) using near infrared reflectance technology. JNear Infrared Spectrosc 13:349-357 (2005).

34 Ferrer-Gallego R, Hernández-Hierro JM, Rivas-Gonzalo JC and Escribano-Bailón MT, Influence of climatic conditions on the phenolic composition of Vitis vinifera L. cv. Graciano. Anal Chim Acta 732:73-77 (2012).

35 Ferrer-Gallego R, Garcia-Marino M, Hernandez-Hierro JM, RivasGonzalo JC and Escribano-Bailon MT, Statistical correlation between flavanolic composition, colour and sensorial parameters in grape seed during ripening. Anal Chim Acta 660:22-28 (2010).

36 Lars S and Svante W, Partial least squares analysis with cross-validation for the two-class problem: a Monte Carlo study. J Chemometrics 1:185-196 (1987)

37 Massart DL, Vandeginste BG, Buydens LM, Lewis PJ, SmeyersVerbeke J and Jong SD, Handbook ofChemometrics and Qualimetrics. Elsevier Science, Amsterdam (1998).

38 Shenk JS, The wonderful world of visible-near infrared spectra: theory and practice, in Near Infrared Spectroscopy: Proceedings of the 11th International Conference, ed. by Davies AMC and Garrido-Varo A. NIR Publications, Norwich, pp. 159-164 (2004).

39 Osborne BG, Fearn T and Hindle PT, Practical NIR Spectroscopy with Applications in Food and Beverage Analysis. Longman Scientific and Technical, Harlow (1993).

40 Siesler HW, Ozaky Y, Kawata S and Heise HM, Near Infrared Spectroscopy: Principles, Instruments, Applications. Wiley-VCH, Weinheim (2002). 